\title{
Colonialidad del saber jurídico y derecho neo-constitucional en Colombia'
}

\author{
Jose Daniel Fonseca-Sandoval
}

jfonsandoval@hotmail.com

Artículo corto de investigación recibido el 12/04/2018

y aprobado el 21/07/2018

\section{Cómo citar este artículo:}

Fonseca Sandoval, J. (2018). Colonialidad del saber jurídico y derecho neo-constitucional en Colombia. TransPasando Fronteras, (12).

\footnotetext{
${ }^{1}$ El presente texto es inédito pero sirvió de base para la ponencia "Derecho neoconstitucional y colonialidad del saber jurídico en Colombia" que fue compartida en la Mesa temática 10: Colonialidad, Estado y Gubernamentalidad del III Congreso de Estudios Poscoloniales y IV Jornadas de Feminismo Poscolonial - "Interrupciones desde el Sur: habitando cuerpos, territorios y saberes", que tuvo lugar del 10 al 12 de diciembre de 2016 en la Universidad de San Martín y la Universidad de Buenos Aires en la capital de Argentina.

${ }^{2}$ Estudiante de la Maestría en Derecho (Modalidad Investigación) de la Universidad ICESI de Cali, Colombia. Profesional en derecho de la Universidad Santo Tomás de Bucaramanga. Asistente de Docencia e Investigación de la Facultad de Derecho y Ciencias Sociales y el Centro de Estudios Sociales y Políticos Interdisciplinares (CIES) de la Universidad ICESI. Investigador de la Red de Antropología de la Biopolítica, adscrita a la Asociación Latinoamericana de Antropología (ALA). Miembro del comité editorial de la Revista Estudiantil Trans-pasando Fronteras
} 


\section{Resumen}

En Colombia, las teorías de la argumentación, interpretación racional y corrección del derecho se han consolidado como lecturas dominantes para la labor judicial. La teoría jurídica hegemónica promueve la creación de una cultura jurídica excluyente, funcional a un conocimiento restringido. Los significados y palabras del lenguaje jurídico se convierten en herramientas de control sobre los grupos sociales que los desconocen. La jurisprudencia de la Corte Constitucional colombiana (devota al constitucionalismo europeo y estadounidense) es incomprensible para los no-abogados, lo que genera una opacidad del derecho, un ocultamiento del funcionamiento y usos del discurso dominante referido. El presente texto afirma que el constitucionalismo dogmático y occidental se ha convertido en una centralidad discursiva en Colombia, lo que genera una colonialidad del conocimiento jurídico. Asumiré el lenguaje como herramienta de poder y su relación con el conocimiento heredado de la modernidad eurocéntrica, señalaremos los elementos fundamentales del neoconstitucionalismo y su aplicación en Colombia, realizaré comentarios críticos frente a sus postulados sobre el discurso y la cultura jurídica y plantearé las consecuencias de un discurso jurídico unívoco; lo que conducirá a plantear la necesaria decolonización del saber jurídico y la construcción de una educación jurídica pluri-popular frente a un campo jurídico hermético.

Palabras clave: Decolonialidad; Neoconstitucionalismo; Saber jurídico. 


\section{Coloniality of juridical knowledge and neoconstitucionalism in Colombia}

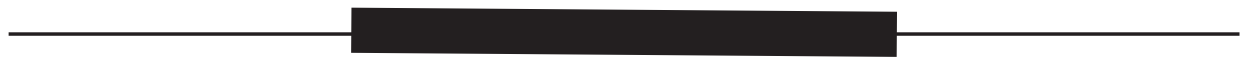

\section{Abstract}

In Colombia, the argumentative, rational interpretation and correction of the law theories have been consolidated as dominant readings for the judicial labor. The juridical hegemonic theory promotes the creation of a juridical exclusive, functional culture to a restricted knowledge. The meanings and words of the juridical language turn into tools of control on the social groups that they do not know. The jurisprudence of the Constitutional Colombian Court (devout to the European and American constitutionalism) is incomprehensible for the non-attorneys, which generates an opaqueness of the right, a concealment of the functioning and uses of the dominant above-mentioned speech. The present text affirms that the dogmatic and western constitutionalism has turned into a discursive centrality into Colombia, which generates a coloniality of the juridical knowledge. I will assume language as tool of power and his relation with the knowledge inherited from the eurocentral modernity, we will indicate the fundamental elements of the neoconstitucionalism and his application in Colombia, I will realize critical comments opposite to his postulates on the speech and the juridical culture and will raise the consequences of a juridical univocal speech; what it will lead to consider the necessary decolonization of juridical knowledge and the construction of a juridical pluripopular education opposite to a juridical hermetic field.

Key words: Decoloniality; neoconstitucionalism; juridical knowledge. 


\section{Introducción}

En el libro Teoría Crítica Constitucional, el profesor Ricardo Sanín (2009) menciona que quien define el lenguaje tiene el poder. La afirmación es pertinente respecto al funcionamiento del derecho constitucional colombiano, pues diagnostica la instrumentalización del discurso jurídico como herramienta de dominación. La lectura racional y lógico-argumentativa del derecho se ha convertido en un paradigma incontrovertible, en detrimento de un constitucionalismo crítico y socio-cultural latinoamericano. Esto representa un colonialismo del saber y del lenguaje, que admite la construcción artificial y dogmática de los usos y restricciones del conocimiento jurídico.

En Colombia, las teorías de la argumentación, interpretación racional y corrección del derecho se han consolidado como corrientes hegemónicas para la labor judicial. Las alternativas de pensamiento jurídico crítico son calificadas como reaccionarias: la posibilidad real de transformar el discurso jurídico estatal y jurisdiccional queda limitada a escenarios académicos periféricos. Históricamente, se acusa a la teoría crítica de ser no-científica y especulativa; lo que descalifica los múltiples "derechos otros" que el pensamiento crítico reivindica y visibiliza.

Pero ¿qué surge de una revisión exhaustiva de la presunta objetividad y razonabilidad de la dogmática jurídica? La teoría jurídica hegemónica promueve la creación de una cultura jurídica excluyente, funcional a un conocimiento restringido. Los significados y palabras del lenguaje dominante del derecho se convierten en herramientas de control sobre los grupos sociales que los desconocen. La jurisprudencia de la Corte Constitucional colombiana (devota al constitucionalismo europeo y estadounidense) es incomprensible para los no-abogados, lo que genera una opacidad del derecho, un ocultamiento del funcionamiento y usos del 
discurso dominante referido. Paradójicamente, los jueces resultan emisarios de lo intraducible al conocimiento popular: deciden en función de fórmulas, teorías y argumentos, que pretenden la racionalización y certeza del derecho, pero que desconocen su indeterminación y profundo contenido político, social e ideológico.

Nuestra intervención sostiene que el constitucionalismo dogmático y occidental se ha convertido en una centralidad discursiva en Colombia, lo que da continuidad a una antiquísima colonialidad del conocimiento jurídico. Para tal fin i) abordaremos el lenguaje como herramienta de poder y su relación con el conocimiento heredado de la modernidad eurocéntrica, ii) señalaremos los elementos fundamentales del neoconstitucionalismo y su aplicación en Colombia, realizaremos comentarios críticos frente a sus postulados sobre el discurso y la cultura jurídica y plantearemos las consecuencias de un discurso jurídico unívoco, que despoja a los sujetos de su capacidad de expresión; iii) lo que nos conducirá a plantear la necesaria decolonización del saber jurídico y la construcción de una educación jurídica popular y amplia, que rompa con la idea de campo jurídico elitista y cerrada.

\section{i) Saber (y lenguaje) jurídico hegemónico: discurso colonial y excluyente}

El lenguaje está en disputa. El lenguaje es inventado, simulado y jerarquizado. No es un fenómeno dado, sino un objeto que transita, distorsiona, revuelve todas las áreas del conocimiento. Como se ha dicho hasta la saciedad, sin lenguaje no podríamos pensar (Schaff, 1967) (Camargo \& Hederich, 2010). De estas formulaciones, tal vez la primera es la más importante. Los códigos del discurso, las claves de significación de un lenguaje específico 
no provienen del azar. Supongamos, de forma más específica, que en la cotidianeidad le otorgamos ciertos nombres a los objetos. Sabemos que aquel pedazo de madera, con cuatro patas para sostenerse, es una mesa; que aquel trozo de madera cilíndrica, atravesada por una mina de grafito es un lápiz. La génesis de ese producto final, que es el lenguaje, está en el combate y en el azar. La lucha por la definición del nombre de un objeto está en el campo cultural. El desarrollo social, las estructuras de gobierno, el pensamiento tradicional e idiosincrático, las necesidades y usos del objeto, podrían ser algunos elementos o factores que inclinen la balanza de la denominación.

Al igual que los objetos, que es un terreno de codificación relativamente amable, los hombres nos hemos dado a la tarea de darle una estructura lingüística a las ideas. Los objetos son susceptibles de juicios relativos y sensoriales, como diría (Wittgenstein, 1989): podemos decir que una silla es buena, que es áspera al tacto, que tiene una pata más corta que las otras. En contraste, las ideas nos representan un reto mayor: describirlas a través del lenguaje, condensarlas en los elementos que otorgan las herramientas lingüísticas, y tal vez lo más importante: comunicarlas correctamente, sin que se extravíe su sentido en el ruido del proceso comunicativo.

No es tarea fácil; tal vez es en este escenario donde se ve de mejor forma la lucha por la significación de un fenómeno a través del lenguaje. Foucault (2005) advirtió que la verdad está sometida al choque entre instintos de dominación: no es un amable intercambio de sugerencias, sino un terreno de pendencia. El conocimiento se construye a través de las relaciones de poder que surgen entre los sujetos que intentan expresarlo y definirlo. Escribe el historiador y novelista colombiano Juan Esteban Constaín: 
Se podría decir sin miedo que la historia del pensamiento y del espíritu de Occidente, desde Sócrates, no ha sido sino una enmarañada sucesión de desencuentros, de reyertas de discípulos, de intrigas a la sombra de las universidades. (...) Todas las ideas con que se ha tejido nuestro mundo fueron resultado de la pasión y del combate (Constaín, 2010, p. 63).

\section{a) Discurso (jurídico); verdad y conocimiento}

Entendemos por discurso un conjunto de enunciados que determinan un objeto susceptible de descripción lingüística. El discurso jurídico, en ese sentido, está construido por un conjunto de proposiciones que responden a unas mismas reglas de constitución; a partir de las cuales se formulan los enunciados que integran el conocimiento del derecho. Foucault (2005) refiere que este orden discursivo está marcado, entre otros aspectos, por una reorganización del espacio y por la pregunta acerca de quién realiza el acto enunciativo; por una parte, se determina que el saber jurídico se genera en los tribunales y en las universidades, mientras que por la otra se establece que quien está autorizado para emitir enunciados del discurso del derecho es el profesional en la materia: el abogado, el juez o el académico.

El lenguaje jurídico, sea teórico (sobre el sistema jurídico) o meta-teórico (sobre la filosofía que da sentido al pensamiento que origina el orden jurídico), constituye un discurso de verdad sobre el derecho: los conceptos, ideas y normas que definen los enunciados que son válidos en el campo jurídico; esto significa que a los juristas les corresponde usar las herramientas propias de dicho lenguaje, con el fin de dar certeza y distinción a su ejer- 
cicio profesional y mantener la posición social privilegiada que ocupan. Foucault (2005) plantea que un discurso es controlado o sometido por dos herramientas vitales: el ritual y la disciplina. Recuerda el filósofo francés que "en toda sociedad la producción del discurso está a la vez controlada, seleccionada y redistribuida por ciertos procedimientos que tienen por función conjurar sus poderes y peligros, dominar el acontecimiento aleatorio y esquivar su pesada y temible materialidad".

El ritual consiste en las maneras, circunstancias, gestos y demás signos que deben acompañar las formulaciones del sujeto enunciador del conocimiento para que lo que expresa sea reconocido como válido; mientras que la disciplina consiste en las reglas de juego que limitan y establecen la producción de enunciados ciertos. El ritual es fácil de detectar en el contexto estético y comportamental que rodea a los abogados: el poder simbólico de la corbata o del maletín, o la relevancia de un código debajo del brazo, al igual que el uso de arandelas lingüísticas a la hora de precisar sus argumentos y alegatos. Por el contrario, la disciplina es una cuestión difícil de establecer, porque implica estudiar las reglas que determinan el grado de verdad de lo que declaran y argumentan los abogados Tuori (1998) hace una pertinente y acertada clasificación de lo que denomina niveles del derecho: uno superficial o de validez, otro que contiene los rasgos de una cultura jurídica específica y el último que se denomina "nivel profundo" del derecho. A nuestro juicio las herramientas del ritual y de la disciplina son asignadas a los niveles dos y tres, respectivamente; en todo caso, ambas funcionan para determinar y controlar el discurso jurídico.

Según Touri (1998), la estructura jurídica profunda se caracteriza por ser relativamente estática y perpetuarse en el tiempo, incluso por varias generaciones. Está emparentada con distintos 
conceptos como paradigma o episteme dominante, que escriben los márgenes de la verdad jurídica a partir de distintos mecanismos de control, como los referidos con anterioridad. En otras palabras, la profundidad del derecho, inmutable y dominante, ejerce la vigilancia y el castigo hacia los conocimientos y expresiones jurídicas disidentes y periféricas.

Vale la pena reiterar aquí la frase de Restrepo (2009): quien define el lenguaje, tiene el poder. El control del discurso es la manera arbitraria e indirecta de establecer diferencias entre los que conocen realmente y los que no: un ejemplo de ello es la función que cumplen las Universidades al certificar la profesionalidad exclusiva de sus egresados. Si bien esto pretende una formación más sólida y rigurosa, genera una externalidad de saberes no-oficiales o no-científicos, que resultan marginados de la centralidad discursiva que emiten los diplomas universitarios.

\section{b) Colonialidad del saber jurídico.}

Anibal Quijano (1992) afirma con acierto que la colonialidad no puede estar disociada del pensamiento moderno eurocéntrico: ambos conceptos y sus respectivas prácticas hacen parte de una época de segregación territorial, lingüística y racial, que estableció como centro del mundo a Europa y como satélites, colonias o periferias a lo que hoy se denomina sur global; Centro América y Latinoamérica, África y parte de Asia. Esto implicó un proceso de opresión y aculturación que, en la mayoría de los casos, produjo la erradicación de culturas y tradiciones ancestrales, al igual que la correspondiente imposición de los valores ilustrados y eclesiásticos de los colonizadores europeos. 
Adicional a esta afirmación previa, es oportuno aclarar a qué nos referimos al usar los términos colonialidad y modernidad. Gabriela Veronelli (2016, p. 39) menciona que "la colonialidad refiere (...) un fenómeno integral y global que penetra todos y cada uno de los aspectos y situaciones de la existencia social, en tanto que la distribución de las jerarquías, lugares y roles sociales están racializados y diferenciados geográficamente". En otras palabras, significa el despojo arbitrario y violento de la identidad cultural y de la esencia vital, en cuanto una sociedad (colonizadora) impone a otra (colonizada) un modo de existencia que es ajena a las personas que integran las comunidades saqueadas (de su lengua, de sus formas económicas y políticas, de sus costumbres religiosas).

Definir la modernidad es un ejercicio más complejo. No se puede decir a ciencia cierta si es una época, una forma de pensar el mundo o una manera de entender las relaciones sociales. Tratando de eludir este bache conceptual, Bolívar Echeverría establece algunas características o elementos fundamentales de la modernidad: i) el rechazo de las posturas metafísicas como signo de progreso y la razón cualitativa como nuevo medio de certeza para acceder al saber; ii) la secularización de lo político que trae consigo una lectura principalmente económica del Estado, que funciona como una superestructura funcional a los intereses económicos de la burguesía; y iii) el individualismo igualitario como forma de articulación social que censura la subjetividad misma: todas las personas son igualmente autónomas y por tanto es irrelevante la idea de lo común (Echeverría, 2008, pp. 7-8).

La colonialidad y la modernidad funcionaron de forma simultánea para consolidar un proyecto social global que fundara una totalidad social basada en la homogeneidad de los grupos humanos y en la racionalidad como única vía hacia el conocimiento ver- 
dadero. En ese sentido, como explica Dussel (2000), la hegemonía europea de la época ilustrada consistió en acentuar la fractura del mundo -producto del colonialismo- de forma definitiva, generando una exterioridad que fuera dominada por las formas sociales $y$ epistemológicas europeas.

Este proceso es fundamental para entender la colonialidad del conocimiento, que se da a través de la imposición de los valores y fines modernos a los territorios dominados. Este fenómeno se cumple con un propósito de sometimiento, bajo el eufemismo de facilitar el progreso de las sociedades pre-coloniales. La colonización del saber tiene como elementos fundamentales: i) una perspectiva líneal y continua de la historia, con el fin de imponer a los territorios colonizados un punto de llegada "moderno" y "racional" (Quijano, 1992) y ii) la constante hegemonía de los saberes racionalizados frente a los conocimientos ajenos a las epistemes eurocéntricas.

El caso del derecho no escapa a esta colonización propagada en el tiempo. Si bien las naciones latinoamericanas fueron autónomas desde el siglo XIX, esa libertad es relativa, en cuanto su conocimiento jurídico e instituciones políticas, plasmados en constituciones y códigos civiles, obedecieron a las herramientas, cánones y paradigmas provenientes de la Europa ilustrada y pos-colonial.

Después de la independencia, los distintos países formaron parte del mismo sistema mundial cuyo eje era Europa. En consecuencia tuvieron los mismos constreñimientos comerciales y políticos y recibieron influencias intelectuales similares. En derecho, los países de tradición romanista habían desarrollado un conocimiento que se presentaba como científico y universal. Puede así esperarse que en los distintos países de América Latina los estudios de derecho hayan sido comunes (Pérez, 2004, p. 101). 
A su vez, esto implica que los siglos subsiguientes, hasta la actualidad, han servido para consolidar la modernización y racionalización del derecho en Latinoamérica, la jerarquización de quienes desempeñan la profesión de abogado o juez y la correspondiente exclusividad del lenguaje jurídico como parte de un campo jurídico hermético. Los rezagos o vestigios de la colonialidad del saber jurídico se constituyen como parte, aún vigente, del nivel profundo del derecho, en términos de Kaarlo Touri.

\section{c) Lenguaje jurídico cifrado y hermético; exclusivo y excluyente.}

Establecer una hegemonía en la formulación de los saberes, también implica una dominación a través del lenguaje. Cuenta Veronelli (2016) que en 1492, antes de la llegada de Colón a las tierras latinas vírgenes, se escribió un manual de gramática de la lengua castellana, con el fin de imponer unas reglas lingüísticas al habla y escritura de los pueblos vencidos en las guerras que libró el reino de Castilla.

En el proceso de invención de América Latina ${ }^{3}$, las lenguas que escucharon los colonizadores eran extrañas a la naciente lengua castellana. Es posible inferir que se aplicó una fórmula similar a la ordenada contra los musulmanes derrotados: la dominación política colonial y la anulación de los saberes expresados en lenguas distintas a la castellana española.

${ }^{3}$ Esta forma de decirlo sirve como antítesis o perspectiva alternativa al relato colonial del descubrimiento de América Latina, que aún hoy insiste en concebir al continente como una tierra nueva y vírgen, carente de historia y cultura propias. 
(...) aquello que daba a una lengua el estatus de ser apta para expresar conocimiento era tener una gramática, entonces se puede entender la relación entre conocimiento y ser comunicador un asunto racional; lo que debe contrastarse con la percepción de las poblaciones indígenas como carentes de conocimiento, carentes de lengua e incapaces de comunicación racional (Veronelli, 2016, p. 43).

El trasfondo de la imposición de la lengua sobre los pueblos colonizados o vencidos va más allá del control político y territorial: consiste en establecer la diferencia entre el saber europeo y el saber inferior e incivilizado. Desde la racionalidad moderna, el lenguaje establece cuales lenguas son aptas para que las personas puedan enunciar un conocimiento válido, lo cual redujo significativamente las chances de indígenas, afrodescendientes, mulatos, criollos y demás mezclas raciales, de ser autónomos y libres a la hora de escribir su propio relato cultural y social, que incluye los conocimientos formulados a través de su constitución histórica como grupo humano.

La racionalización eurocéntrica no se detuvo en cuanto finalizó la colonización política, por cuanto la modernidad heredada a la fuerza, como menciona Echeverría (2008), es un proceso largo, difuso y difícil de encasillar en las reglas del tiempo, pues perdura oculto en distintas representaciones simbólicas que mantienen las relaciones de poder coloniales.

El derecho sirve como ejemplo de la consolidación de la colonialidad del saber en Latinoamérica, debido a que las naciones de Suramérica se independizaron de facto, pero no del conocimiento jurídico y del lenguaje del derecho europeo. Basta echar un vistazo a los usos de los conceptos "propiedad", "autonomía" 
o "libertad" para entender el traslado del pensamiento moderno hacia los países recientemente emancipados: eso implica denotar que el lenguaje propio, como capacidad de expresar el conocimiento sobre algo, ha sido controlado desde los inicios de nuestra vida republicana. La historia de las ideas políticas y jurídicas de los países latinoamericanos es una "novela plagiada", según la célebre expresión del peruano Augusto Salazar (1968).

En la actualidad, aun vemos esa difusión del pensamiento jurídico europeo como dominante: los conocimientos que forman a los abogados en Colombia son reproducciones totales, parciales o revisadas superficialmente, de los conceptos, epistemes y doctrinas aplicadas en las naciones "civilizadas" de Europa y Estados Unidos. Esto constituye e integra las reglas del discurso jurídico en Colombia, pues segrega las posibilidades periféricas de formular el derecho distintas a las que expresan las Universidades privadas prestigiosas (cuyos profesores son formados en los centros de saber europeos y norteamericanos más pudientes y reconocidos) ${ }^{4}$ y la Corte Constitucional Colombiana como órgano de cierre y garante de la aplicación correcta de la Constitución Política de 1991.

En términos de Tuori (1998), el nivel profundo del derecho, que funciona bajo la lógica modernidad-racionalidad, establece también una cultura jurídica cerrada, que promueve un campo jurídico hermético y apático a la diversidad epistémica. Así, en el campo social del derecho, solo pueden formular enunciados válidos quienes cumplan los requisitos rituales y disciplinares para

\footnotetext{
4“(...) la educación superior en América Latina a pesar de algunos intentos por ampliar su cobertura sigue siendo de élite, no en el sentido en que lo es por ejemplo la educación jurídica en Estados Unidos, basada en un sistema de selección meritocrática, sino porque ofrece educación solo a un pequeño porcentaje de la población que la requiere y, dentro de ella, solo a las clases más altas." (Montoya, 2008: 32)
} 
acumular lo que Pierre Bourdieu (2000) denomina como capital jurídico. Los sujetos enunciadores del saber jurídico son avalados a partir del uso claro de las herramientas lógicas, racionales y lingüísticas establecidas por las reglas del discurso del derecho. Dichos sujetos acumulan la legitimidad necesaria para explicar, interpretar y modificar el orden jurídico y su funcionamiento, pero siempre atados a los dictámenes de un discurso jurídico cerrado y, como anticipamos, de raigambre eurocéntrica.

De tal suerte que son pocos los sujetos que pueden enunciar el derecho. Los abogados, profesores de derecho, jueces y parlamentarios son quienes dan continuidad al discurso jurídico cerrado. Esto representa una incapacidad de expresión o enunciación sobre el derecho vigente por parte de quienes no son profesionales en derecho, lo cual desemboca en la irrelevancia de los discursos sobre el derecho que se reproducen en la periferia de la institucionalidad y la academia. En la base de este proceso está la pretendida neutralidad y despolitización del derecho, como desarrollo de la pretensión de racionalidad del conocimiento jurídico. "El lenguaje jurídico queda vaciado de contenidos políticos o éticos aparentemente, apareciendo como una forma neutra y universalizable en primera instancia por la propia construcción del razonamiento" (Morales de Setién, 2000, p. 72).

En definitiva, el saber y el lenguaje jurídico quedan supeditados a los enunciados doctos y racionales de los sujetos avalados por el discurso jurídico hegemónico, quienes reemplazan a los antiguos chamanes (indígenas, páganos e impíos) y llenan el vacío de lo sagrado al reemplazarlo por un culto totémico e irreflexivo hacia la formalidad del derecho y su justificación racional. 
En el momento de la génesis del lenguaje, los chamanes, magos y sacerdotes se aseguraron de controlarlo, para que la esencia sagrada de sus conocimientos se transfiera a ellos y que fundamente el poder y la dominación que ejercen sobre sus "sujetos". El terror del hombre primitivo ante los fenómenos naturales lo llevó a preferir otra dominación, que se ejercía por la mediación de la figura del docto chamán. Analógicamente, se podría afirmar que la existencia del mundo jurídico es constitutiva del poder del letrado y de los otros especialistas del derecho, profesores, magistrados, árbitros, quienes controlan el sentido del mismo y, por lo tanto, ejercen poderío sobre los profanos (Saucier, 2015, p. 408).

La cultura jurídica latinoamericana existe a medias, pues es deudora notable de la colonialidad del saber. Esa es la razón por la cual, aún en la actualidad, la teoría del derecho latinoamericana discute de forma vertical y no horizontal con la teoría del derecho europea. Veremos un ejemplo de ello en el Ilamado "neoconstitucionalismo", que resulta una experiencia ilustrativa de lo expuesto.

\footnotetext{
5 Por cuestiones de espacio no podemos discutir aquí las distintas refutaciones que estas aseveraciones causan en la cultura jurídica colombiana, pero basta decir que generan un malestar difícil de superar. Esto por cuanto, según la doctrina del derecho imperante, los trasplantes jurídicos garantizan la independencia de los pueblos frente a la dominación eurocéntrica colonial, pues impiden que se trasladen de manera indiscriminada los modelos de gobierno y epistemologías del derecho y del Estado foráneos. A pesar de que esta apreciación sea noble y consciente, no evita que haya ejemplos que pongan en entredicho la aplicación del pensamiento europeo o norteamericano como mera referencia o inspiración para crear derecho.
} 


\section{ii) Neoconstitucionalismo y derecho neo-constitucional colombiano}

En términos de teoría del derecho, Colombia heredó una corriente previa al neoconstitucionalismo, denominada globalmente como positivismo jurídico. Es ampliamente conocida la influencia del ius-positivismo exegético en la construcción de las primeros Estados-Nación bajo el amparo ideológico de la revolución burguesa en Francia: también la irrupción del ius-positivismo clásico de Hans Kelsen, en función de dotar a la ciencia jurídica de mayor autonomía y certeza. La teoría pura del derecho tuvo una relevancia significativa para la edificación de los órdenes constitucionales de la primera mitad del siglo XX.

Tras la crisis humanitaria y violenta que representó la Segunda Guerra Mundial, la hegemonía de la racionalidad-modernidad fue puesta en duda. ¿Cómo fue posible que los Estados civilizados y racionales-ilustrados de Europa cedieran ante el fascismo y el totalitarismo, desencadenando una confrontación bélica?6 En el ámbito ius-teórico, el paradigma del ius-positivismo kelseniano se vio superado por la implacable violencia practicada por las naciones ilustradas, que hasta entonces aplicaban sistemas de derecho jerárquicos y racionales. El derecho natural tuvo una suerte de renacimiento breve, pues era de suponer su regreso como consecuencia lógica frente al decaimiento del positivismo. No obstante, lo que ocurrió fue diferente: gracias al impacto de las doctrinas del realismo jurídico norteamericano y escandinavo, el derecho pasa a ser formulado más allá de la validez y la formalidad. Este proceso desemboca en lo que hoy conocemos como trialismo ju-

\footnotetext{
${ }^{6}$ Consideramos que esto revela la inestabilidad del proceso racionalista de la ilustración, en cuanto pretendió ocultar o justificar las arbitrariedades y vejámenes practicados por los colonizadores respecto a los territorios y pueblos "vírgenes".
} 
rídico, que consiste, básicamente, en una mirada trilemática del derecho: desde su validez, eficacia y legitimidad.

De forma paralela, se solidifica la importancia de la Organización de Naciones Unidas y se consolida un discurso global sobre los derechos humanos. Este elemento ético universal será fundamental para explicar la conformación de las constituciones de la segunda mitad del siglo XX, sobretodo en sus versiones latinoamericanas. En los distintos países del cono sur se acogió la tesis de la positivización de los derechos humanos como derechos fundamentales (Alexy, 2005). En el caso específico de Colombia, la Constitución de 1991 (vigente en la actualidad) creó el mecanismo de la acción de tutela para la protección de dichos derechos, a la vez que creo el control de constitucionalidad y revisión de los amparos (o tutelas) en cabeza de la Corte Constitucional.

En ese sentido, Colombia heredó la tendencia global para la integración de la ética universal de los derechos humanos al ya establecido sistema de derecho racional y formal. Esto implicó un viraje en la resolución de conflictos jurídicos, pues condicionó a los jueces a la no-vulneración de derechos fundamentales y a seguir el precedente jurisprudencial de la Corte Constitucional al respecto. En definitiva, se hizo popular el término "neoconstitucionalismo", para designar los métodos de interpretación, rigurosos y razonables, que pretenden otorgar certeza y corrección al derecho a partir de los principios o valores constitucionales.

\section{a) ¿Qué es el neoconstitucionalismo?}

El neoconstitucionalismo no es propiamente una teoría del derecho, ni tampoco una metodología o epistemología. A nuestro 
juicio, es más bien una construcción doctrinal que tiene origen en las escuelas constitucionalistas de Italia y Alemania de finales del siglo pasado. Entre sus autores de cabecera suelen mencionarse a los italianos Gustavo Zagrebelsky (2003) y Susana Pozzolo (1998) y en el ámbito alemán destaca la obra de Robert Alexy (2008) como crítica o amplificadora de los escritos e ideas del norteamericano Ronald Dworkin, (2007).

Inicialmente catalogado como "nuevo derecho", el neoconstitucionalismo surge como alternativa judicial para la materialización del discurso ético universal de los derechos humanos; pretende dar un papel primordial a la jurisprudencia dentro del sistema de fuentes de los ordenamientos nacionales y establecer una preponderancia del contenido valorativo de la constitución, que denominaremos moral-política constitucional (Pozzolo, 1998). A juicio del catedrático español Jose Antonio García Amado, los cometidos principales del neoconstitucionalismo son

i) reforzar la influencia política de la presunta ciencia jurídico-constitucional e ii) impulsar un judicialismo que subvierte la relación entre los poderes constitucionales, pone en jaque el principio democrático y la soberanía popular y desdobla las propias constituciones, haciendo que ciertos derechos materializados y fuertemente vinculados a valores morales sustanciales imperen absolutamente sobre los derechos constitucionales de tipo político (Garcia Amado, 2010, p. 131).

Aunque más adelante expresaremos por qué nos apartamos del segundo cometido establecido por García Amado (2010) consideramos que su mención es indispensable para entender los conflictos que suscita una práctica judicial que cierra el campo jurídico 
en torno a lo que deciden los jueces. Por otra parte, el primer cometido referencia la concentración del saber jurídico en la llamada "ciencia jurídico-constitucional", lo que lleva a una segregación de los discursos constitucionales no-oficiales o no-hegemónicos y de otras áreas del saber que pueden ayudar a la resolución judicial de los retos problemáticos que enfrentan los jueces.

Otra característica mencionada por García Amado (2010) consiste en la relación de los profesores de derecho con el neoconstitucionalismo. Según el profesor español, alrededor de la doctrina referida, existe una especie de complejo "académico-judicial", el cual proviene de un aparente compromiso ético y objetivo (si es que acaso es posible tal cosa) con la Constitución y sus fundamentos axiológicos. García es incisivo a la hora de denunciar que, detrás de esta presunción de razonabilidad, se esconde un entramado que

(...) funciona a la perfección porque los jueces ven en esa doctrina la justificación perfecta para la ampliación de sus poderes frente al legislador y de su condición de oráculos de la Constitución profunda, mientras que los profesores colman sus aspiraciones cuando ven a los jueces construir la nueva constitución con los elementos que ellos les van proponiendo (Garcia Amado, 2010, p. 133).

Desde un punto de vista menos crítico y escéptico, podemos resumir que los principales planteamientos del neoconstitucionalismos parten de: i) un sistema jurídico rígido en el que la constitución tiene una supremacía normativa, con ii) un modelo de constitucionalismo fuerte, en el que exista control de constitucionalidad y iii) un órgano constitucional que concentre la labor jurisdiccional en torno a la garantía de los derechos y principios fundamentales. Coincidimos con la descripción breve y categórica que ensaya María Ángeles Ahumada: 
El neoconstitucionalismo parece servir como término genérico para referirse a todas aquellas teorías explicativas y justificativas de ciertas prácticas constitucionales que, en conjunto (y para abreviar) alientan un tipo de constitucionalismo fuertemente judicialista y judicializado, fundamentalista en materia de definiciones y más o menos abiertamente desconfiado del principio de la mayoría (Ahumada, 2009, pp. 133-134).

De igual forma, la catedrática italiana Susanna Pozzolo (1998) establece algunos elementos esenciales, a modo de contradicciones o debates que se producen a la hora de instaurar la doctrina neoconstitucional.

- Principios versus normas: describe la diferencia entre la naturaleza conceptual de los principios frente a las otras reglas de cualquier ordenamiento (Rodríguez, 1997); mientras que aquellos son abstractos, generales y con un contenido valorativo, estas son determinadas por la estructura kelseniana que contiene un sujeto, un verbo condicionante y una consecuencia jurídica. Para el neoconstitucionalismo es fundamental establecer la diferencia, pues determina que los principios tienen una mayor jerarquía en la aplicación del derecho.

- Ponderación versus subsunción: debido a que los principios y derechos fundamentales tienen un contenido axiológico, los problemas que se susciten entre ellos no se pueden resolver a través de la mera subsunción. Se requiere otro método que contemple el peso general o específico de los principios, para poder balancear su valía frente a un caso concreto; a este método se le denomina ponderación (Alexy, 2005). 
- Constitución versus independencia del legislador: si el texto constitucional tiene un contenido valorativo de mayor jerarquía en el ordenamiento, esto establece unos límites a la autonomía del legislador para establecer las reglas del sistema jurídico.

- Juez versus libertad del legislador: el órgano constitucional de mayor jerarquía, adquiere una relevancia tal que su jurisprudencia se constituye como fuente primaria del derecho, lo que genera, en consecuencia, la asignación de un rango inferior a las leyes creadas por la rama legislativa.

\section{b) ¿Por qué Colombia tiene un derecho neo-constitucional?}

El caso de Colombia es particularmente ilustrativo respecto a la influencia del neoconstitucionalismo en Latinoamérica. En gran parte debido a la multiplicidad de familias jurídicas que integran e influencian el orden jurídico nacional, como es el caso del Código Civil de 1887 (vigente aún), transcripción de la legislación post-revolucionaria francesa (Pérez Perdomo, 2004); de la Constitución Política de 1991, que toma como referencia la Constitución española de 1986 y las experiencias constitucionales Alemanas (Constitución de Weimar y Ley Fundamental de Bonn).

No es posible afirmar con contundencia que no tenemos historia o teoría del derecho propias, pero podemos advertir que la originalidad y la imaginación no han caracterizado la construcción del sistema constitucional colombiano, a pesar de que los trasplantes de dichas normas se hayan hecho adecuadamente. Esto se debe a que la colonialidad del saber se ha extendido más allá de la independencia territorial de Latinoamérica, y aún mantiene incólume la violencia epistémica que ejerce Europa (antes 
y ahora) y Estados Unidos (ahora) sobre las naciones suramericanas (Castro-Gomez, 2000). Ellos piensan, aplican y sustentan, mientras nosotros aguardamos, trasplantamos y replicamos.

El profesor colombiano Leonardo García Jaramillo (2008) defiende la relevancia de la doctrina neoconstitucional en Colombia. Sustenta que existen tres elementos que dieron lugar a esta corriente enfocada en el ámbito judicial, la cual admite tuvo origen a partir de textos doctrinales desde los años setenta: En primer lugar, la nueva constitución de 1991; liberal, republicana y democrática, que según García Jaramillo se encargó de establecer un catálogo de derechos fundamentales y establecer el contenido materialpolítico del texto constitucional, además de otorgar los amparos suficientes a los ciudadanos para garantizar sus derechos ante los abusos u omisiones del Estado. En segundo lugar, las prácticas jurisprudenciales han suministrado al juez la posibilidad de crear derecho para suplir las necesidades jurídicas de los ciudadanos y solventar las lagunas o antinomias. Y en tercer lugar, el rol del juez como protagonista esencial de la corrección del derecho, en función de los derechos y principios fundamentales constitucionales.

Concedemos a García Jaramillo (2008) su aporte a la caracterización del neoconstitucionalismo, pero consideramos desacertada la enunciación que hace respecto a la injerencia que este ha tenido en Colombia. Siguiendo a Lascarro (2012), el orden jurídico colombiano no está solo influenciado por una doctrina neoconstitucional, sino más bien se constituye como un derecho neoconstitucional; pensado desde una dogmática-jurídica que afianza la idea de campo jurídico a-político, ampliamente influenciado por la ideología liberal-moderna eurocéntrica. De tal suerte que este derecho está cerrado en sí mismo, es más procedimiento que acción, más ponderación que lucha social y transformaciones culturales. 


\section{c) Anotaciones críticas frente al derecho neoconstitucional colombiano.}

El neoconstitucionalismo pretende evadir la mirada lógica del positivismo jurídico, aludiendo a que el derecho tiene un contenido moral-político; no obstante, a nuestro juicio esta intención resulta insatisfecha en la medida que solo sea permitida una vía racional y razonable (concentrada y jerárquica) para resolver una confrontación entre principios o derechos fundamentales (nos referimos al ya referenciado test de ponderación). La salida del neoconstitucionalismo resulta igualmente formalista, pues pretende otorgar un peso específico a los principios constitucionales, sometiéndolos a la interpretación y argumentación del juez, antes que a otros posibles criterios de orden sociológico, filosófico o antropológico que sean de mayor relevancia para comprender la complejidad de los problemas abordados por el Tribunal Constitucional.

Por otra parte, la objetividad el derecho neo-constitucional está en entredicho. Pese a que su pretensión es la de dar certeza racional y razonable a las decisiones judiciales, algunos autores plantean que los jueces no deciden de manera objetiva, sino que sus posiciones son tomadas antes de pensar los argumentos jurídico-constitucionales que utilizarán. El jurista italiano, Paolo Comanducci, cuestiona tanto la idea de una moral objetiva constitucional (a la que nos referimos a continuación) como a la postura del juez aséptico y ecuánime

Suponiendo incluso que exista, la moral objetiva no es conocida ni compartida por todos los jueces; no existe en nuestras sociedades, una moral positiva compartida por todos los jueces; los jueces no 
son coherentes en el tiempo con sus propias decisiones, y no construyen un sistema consistente de derecho y moral para resolver los casos; los jueces no siempre argumentan y deciden racionalmente (Comanducci, 2009, p. 109).

En este sentido también son reconocidos los trabajos de Jeremy Waldron (2012), Juan Antonio García Amado y de Duncan Kennedy (2010), que descartan la neutralidad del juez en la interpretación constitucional y por el contrario afirman que la ideología es un elemento condicionante e imperante en las decisiones judiciales. Esto no significa que sea aceptable la decisión caprichosa de los magistrados, pero si aterriza y despliega un panorama más realista y consciente de la humanidad de los jueces y de su vulnerabilidad a los juicios de valor. Es afortunado e interesante el comentario de Pozzolo (1998): "La perspectiva que la doctrina neoconstitucionalista toma en consideración, quedando inamovible el objetivo histórico del constitucionalismo, parece ser unívocamente la del 'buen juez dotado de buen criterio'”.

Desde otro punto de vista, la materialidad axiológica, contenida en la Constitución, se erige como parte de un proyecto ideológico que niega la interpelación horizontal discursos jurídicos plurales, y que establece, bajo el amparo de la neutralidad, una nueva fe arbitraria y elitista depositada en el trabajo del Tribunal Constitucional. En ese sentido, lo moral y lo político se funden o diluyen en la axiología constitucional y son restringidos ante el escrutinio y análisis, en apariencia neutral y razonable, que realizan los jueces; desechando la posibilidad de transformación institucional y social desde el derecho, bajo el amparo de otras morales y políticas posibles. Lo jurídico se ha convertido en un campo de alta sofisticación conceptual, que realiza ampliaciones de derechos 
fundamentales individuales, pero que se mantiene limitado para ejercer verdaderas mutaciones jurídico-políticas estructurales, a favor de las poblaciones marginadas en lo económico y en lo cultural. No queremos decir con esto que la labor de la Corte sea innecesaria o equivocada, por cuanto generaría que las mayorías dicten, de manera igualmente arbitraria y violenta, lo que se debe entender por moral constitucional y por derecho. No obstante, a nuestro juicio existe una excesiva concentración del discurso del derecho en el Tribunal Constitucional, que impide a otros discursos constitucionales la interpelación de los razonamientos de la Corte. Por otra parte, la Corte Constitucional ejerce una labor razonable que desconoce la indeterminación del derecho (Kennedy, 2006), y se conforma y engaña con la obtención racional de una respuesta correcta (única o variable según el caso concreto).

La tarea de la Corte debería reconocer el profundo carácter ideológico que subyace en la creación y aplicación del derecho, al igual que servir de receptor, y no de barrera, frente a las distintas manifestaciones periféricas que promueven la reivindicación de sectores poblacionales olvidados y oprimidos, y la consecuente creación de nuevos derechos humanos propios y auténticos ${ }^{7}$. Contrario a algunos cuestionamientos comunes frente a la doctrina neoconstitucional, no nos preocupa la pugna entre el poder judicial y el legislativo debido a la concentración del poder deci-

\footnotetext{
${ }^{7}$ La profesora Susana Villavicencio (2007) afirma que los ciudadanos han sido despojados de lo que se domina el 'derecho a tener derechos', que no es otra cosa que la posibilidad de discutir, deconstruir e inventar el contenido político de los derechos constitucionales, respetando los avances y aciertos del sistema jurídico en materia de derechos fundamentales. La profesora Villavicencio sostiene una idea que es más acorde a la potencia creativa-común: tenemos derecho a tener derechos, a crearlos, a repensarlos y a modificarlos. Los movimientos sociales expresan esta interesante imaginación institucional y constitucional.
} 
sional y democrático en el primero, ni tampoco el carácter contra-mayoritario que tiene la jurisprudencia de la Corte Constitucional. Dicho esto, nuestro interés está enfocado en la necesidad de una crítica punzante frente a una doctrina hegemónica que pretende establecerse como incontrovertible o irreemplazable, y que además proviene de filosofías y teorías del derecho prestadas o "plagiadas". Probablemente esto no sea responsabilidad de la doctrina neoconstitucional de manera abstracta, sino de sus principales constructores: académicos y jueces.

Bien expresa García Jaramillo (2008) que "la jurisprudencia (...) se ha constituido en fuente primaria de la conciencia jurídica colombiana, es decir, en la principal fuente de nuestra forma de comprender y practicar el derecho en el ámbito académico y profesional" (pp. 300-301). Esta frase resulta clarificadora respecto a quienes son los sujetos que enuncian válidamente el discurso jurídico dominante, que hemos decidido denominar derecho neoconstitucional. La cultura jurídica elitista resulta un ejemplo del carácter exclusivo y excluyente del saber sobre el derecho, generando una brecha entre los abogados, jueces o profesores de derecho y los no-abogados. Dada la importancia del neoconstitucionalismo como doctrina hegemónica en la aplicación del derecho y la reivindicación de derechos fundamentales, es paradójico que los ciudadanos no estén invitados a interpelar, de forma horizontal, dicho conocimiento cifrado.

Irónicamente, el neoconstitucionalismo, que pretende ser una suerte de forma razonable de aplicar una moral política constitucional, resulta un proceso inaprensible para los no iniciados en los conceptos clave del discurso jurídico unívoco: ponderación, argumentación, principios y reglas o democracia sustancial. No podemos dejar de preguntarnos el motivo de esta disparidad vertical; la 
hegemonía de los jueces y de los profesores de derecho afines al neo-constitucionalismo se consolida, mientras la comprensión del derecho por parte de los sujetos de derecho, como forma de empoderamiento, queda relegada a un último plano de reflexión.

Acierta el profesor argentino Carlos Cárcova (1998) al expresar el poco interés de la academia y de los sistemas jurídicos y políticos en Latinoamericana por la formación jurídica de sus ciudadanos: expresa Cárcova (1998) que el derecho local se ha preocupado por el tema de la ignorancia del derecho, sobre todo en materia penal, pero se ha olvidado por completo de su comprensión. Una cosa es que a las personas les esté prescrita la ignorancia del derecho, pero otra cosa es que lo entiendan o no; que puedan explicar la función del derecho y más específicamente la forma en que toma decisiones jurisdiccionales el Tribunal Constitucional respecto a los derechos que los atañen.

No podemos aceptar aquella idea de que el derecho es responsabilidad exclusiva de los más aptos y calificados, por cuanto sería ceder ante un campo jurídico hermético que hemos criticado en los apartados anteriores: no hay razón que justifique la despolitización del derecho, pues esto significaría la destrucción de la relación inescindible entre lo político y lo jurídico: lo primero como tensión constante entre diferencias y singularidades (Mouffe, 1999) y lo segundo como las herramientas que sirven a los sujetos de derecho para transformar su realidad socio - cultural y cimentar el camino hacia el buen vivir común.

En conclusión y desde una perspectiva crítica y en clave decolonial (Quijano, 1992), el neo-constitucionalismo i) establece una centralidad discursiva, que hace único y hegemónico el derecho constitucional del Estado, impidiendo este sea interpelado, distorsionado o re-pensado a partir de las reflexiones de los múltiples discursos 
alternos y periféricos que circulan al margen de la institucionalidad; y ii) genera una opacidad del derecho, en cuanto construye una cultura jurídica exclusiva y excluyente que impide a los ciudadanos interpelar por sí mismos, bajo sus propios cuestionamientos y criterios, las resoluciones judiciales del Tribunal Constitucional o las posiciones de la doctrina hegemónica del derecho.

\section{iii) Consideraciones finales: de-colonizar el derecho constitu- cional y procurar una educación jurídica popular}

En Elementos para una sociología del campo jurídico, Pierre Bourdieu (2000) aborda el problema del hermetismo del campo jurídico en relación con la correspondiente incomprensión del derecho por parte de las clases sociales y sujetos que no pueden integrar dicho discurso. Respecto al texto referido, comenta Morales de Setién que por desconocimiento comprendemos el

(...) conjunto de mecanismos, de prácticas que se dan a un interior del campo y que legitiman la forma de capital jurídico que se posee de manera arbitraria. Los que trabajamos en teoría legal conocemos bien el rechazo que en muchos prácticos producen las teorías críticas del orden legal, especialmente las que atacan la idea de determinación o congruencia del ordenamiento jurídico (Morales de Setién, 2000, p. 62).

El neoconstitucionalismo plantea que un sistema jurídico i) está determinado y ii) se predica coherente en función de la axiología constitucional. Por esa razón, la apatía frente a las múltiples vertientes de la teoría crítica, que pretende disolver los límites del campo jurídico, está justificada para perpetuar la importancia de 
los abogados, jueces y doctrinantes en la formulación de un lenguaje jurídico excluyente; lo que no deja de ser una consecuencia negativa de los esfuerzos válidos y necesarios para reivindicar derechos por las vías institucionales y haciendo uso de las herramientas de la ciencia jurídico-constitucional.

En ese sentido, nuestra propuesta va más allá de desconocer el derecho neo-constitucional o su legitimidad. Buscamos la fundamentación y las razones de que las distintas singularidades y ciudadanías, urbanas y rurales, puedan expresarse para cuestionar, de forma horizontal, el contenido político de la Constitución. Nuestra pretensión radica en de-construir el derecho moderno y eurocéntrico que aún hoy sigue siendo nuestro punto de partida y de llegada epistémico. Para ello consideramos necesario poner en marcha dos tareas fundamentales: a) de-colonizar el pensamiento, el saber y el lenguaje jurídico, y por otro lado b) la construcción de una educación jurídica popular que reivindique la capacidad de expresión y emancipación de las subjetividades oprimidas frente al derecho.

Lo primero necesita de una ruptura decolonial, en la cual las lecturas o interpretaciones foráneas sirvan a la deconstrucción del discurso de la modernidad ilustrada en América Latina, específicamente alrededor del derecho y de lo político. La emancipación epistémica sugiere la construcción de nuevas epistemologías y modos de construir la teoría desde el sur, y a su vez una posición escéptica pero incluyente de las revisiones intelectuales críticas europeas: en ello la teoría crítica norteamericana y el posestructuralismo francés pueden ser de gran utilidad (no dominante y no impuesta) para la reformulación del pensamiento propio; de un relato jurídico-cultural y constitucional propio que sirva de punto de partida y de llegada.

El proceso de construcción se puede dar en torno a lo que Santos (2010) denomina como ecología de saberes. La idea del pen- 
sador portugués parte de una situación de inter-conocimiento en la que, independientemente de la jerarquía ocupada en la geopolítica del saber, toda producción epistémica implica un anverso de ignorancia. En este escenario, es necesaria la refutación del conocimiento como totalidad racional o científica, proveniente de determinados centros de producción hegemónica, y el correspondiente reconocimiento de prácticas y experiencias alternativas que dan origen a saberes e ignorancias plurales e intercomunicadas. En el ámbito del derecho, el deslinde de la violencia epistémica requiere de un compromiso con la apertura del campo jurídico a los discursos jurídicos periféricos que atraviesan el continente nuestro-americano.

Siguiendo los postulados de Santos, la escritura de una epistemología jurídica del Sur debe admitir la multiplicidad de discursos constitucionales, encontrar la forma en que las instituciones estatales, regionales, comunitarias o informales sirvan para generar y consolidar un discurso jurídico-constitucional incluyente y abierto; integrado por las distintas razas, culturas, etnias, tribus urbanas y demás subjetividades contemporáneas o ancestrales oprimidas.

Entiendo por epistemología del Sur el reclamo de nuevos procesos de producción y de valoración de conocimientos válidos, científicos y no científicos, y de nuevas relaciones entre diferentes tipos de conocimiento, a partir de las clases y grupos sociales que han sufrido de manera sistemática las injustas desigualdades y las discriminaciones causadas por el capitalismo y el colonialismo (Santos, 2010, p. 49).

Lo segundo hace parte de una modificación del papel que tiene la pedagogía en la educación formal. Como lo hemos estudiado y ampliado en otro trabajo (Fonseca \& Forero, 2017), las prácti- 
cas educativas modernas tienen la intención de dominar y someter las pasiones, las emociones y la curiosidad del aprendiz, lo que degenera en una estructura jerárquica del saber en la que los docentes tienen todo el control disciplinar sobre los alumnos. En la educación jurídica la cuestión no es distinta, ya que las mismas Universidades consolidan una formación en derecho que se predica exclusiva y excluyente, a favor de la continuidad del status social del abogado y no al servicio de las reivindicaciones sociales y económicas de poblaciones marginadas y aún menos como parte de un ejercicio profesional que contribuya a la comprensión del derecho de los no-abogados.

Respecto de cualquier trabajo que esté fuera del sistema establecido -por ejemplo, asistencia jurídica para los pobres y práctica jurídica vecinal- [los profesores] convencen a los estudiantes de que ese tipo de trabajo, aunque moralmente aceptable, es inevitablemente aburrido y plantea pocos desafíos, y que las posibilidades de alcanzar el nivel de vida propio de un abogado son reducidas o no existen. Estos mensajes son absurdos -racionalizaciones de profesores de derecho que quisieran estar más arriba, temen la decadencia de su status y, sobretodo, detestan la idea de riesgo. La práctica de servicios legales comunitarios, por ejemplo, es mucho más interesante y estimulante, aun cuando haya mucho trabajo, que lo que hace la mayoría de abogados que trabajan en estudios dedicados al derecho empresarial (Kennedy, 2004, p. 134).

Pero más allá de la comprensión del derecho, hace falta recuperar la historia cultural y jurídica extraviada gracias a las enciclopedias de derecho romano y francés: nuestra enseñanza del derecho está basada en una estructura lineal del pensamiento global, donde los países latinoamericanos han sido borrados de los libros que relatan 
la historia de las ideas y las prácticas jurídicas. ¿Será cierto que antes de que llegaran los colonizadores no existía ninguna clase de derecho autónomo? ¿Ese olvido no representa acaso la forma en que se produce la violencia epistémica por parte de los países "desarrollados"? No es posible predicar una decolonización del saber jurídico sino reconstruimos la historia del derecho suramericano, antes, durante y después de la colonización, para así poder comprender, de manera independiente y profunda, la construcción cultural de nuestra narrativa jurídica y constitucional.

Los elementos antes descritos deben integrar una propuesta de educación jurídica popular, que reconstruya y reconozca los derechos otros silenciados, periféricos y marginales, para poder realizar de forma más clara y contundente nuestra independencia intelectual y cultural. Para lograrlo es indispensable hacer frente a la concentración del discurso jurídico en las élites académicas y judiciales, al igual que promover procesos de aprehensión del derecho como herramienta paradojal, en el sentido que le atribuye Carlos Cárcova: como instrumento de dominación que a la vez es vía de transformación social de los grupos subalternizados. La propuesta de educación jurídica popular implica cambios curriculares que controviertan la fuerte influencia de las corrientes occidentales en la formación de abogados, una reingeniería de las facultades de derecho, de sus rituales, jerarquías y saberes dogmáticos, y una noción de la Universidad como espacio de intercambio intercultural de las distintas posibilidades de conocimiento e ignorancia. 


\section{Referencias bibliográficas}

Ahumada, M. Á. (2009). Neoconstitucionalismo y Constitucionalismo. En P. Comanducci, D. González, \& M. Á. Ahumada, Positivismo jurídico y neoconstitucionalismo (págs. 123-157). Madrid: Fundación Coloquio Jurídico Europeo.

Alexy, R. (2005). Teoría del discurso y derechos humanos. Bogotá: Universidad Externado.

Alexy, R. (2008). El concepto y la naturaleza del derecho. Madrid, España: Marcial Pons.

Bourdieu, P. (2000). Elementos para una sociología del campo jurídico. En P. Bourdieu, \& G. Teubner, La fuerza del derecho (págs. 153-220). Bogotá: Siglo del Hombre Editores.

Camargo, A. \& Hederich, C. La relación lenguaje y conocimiento y su aplicación al aprendizaje escolar.

Cárcova, C. (1998). La opacidad del derecho. Madrid: Editorial Trotta.

Castro-Gomez, S. (2000). Ciencias sociales, violencia epistémica y el problema de la "invención del otro". En E. (. Lander, La colonialidad del saber: eurocentrismo y ciencias sociales. Perspectivas Latinoamericanas (pág. 246). Buenos Aires: CLACSO.

Comanducci, P. (2009). Constitucionalización y neoconstitucionalismo. En P. Comanducci, D. González, \& M. Á. Ahumada, Positivismo jurídico y neoconstitucionalismo (págs. 85-112). Madrid: Fundación Coloquio Jurídico Europeo.

Constaín, J. E. (2010). ¡Calcio! Bogotá: Editorial Seix Barral.

Dussel, E. (2000). Europa, modernidad y eurocentrismo. En E. L. 
(comp.), La colonialidad del saber: eurocentrismo y ciencias sociales. Perspectivas latinoamericanas (pág. 246). Buenos Aires, Argentina: CLACSO, Consejo Latinoamericano de Clencias Sociales.

Dworkin, R. (2007). La justicia con toga. Madrid: Marcial Pons.

Echeverría, B. (2008). Un concepto de modernidad. Revista Contrahistorias No. 11, 7-18.

Fonseca, J. D. \& Forero, H. (2017). La educación jurídica: de la pedagogía moderna iuspositivista a la pedagogía crítica transdisciplinar y pluricultural (Inedito).

Foucault, M. (2005). El orden del discurso. Buenos Aires: Tusquets Editores.

Garcia Amado, J. A. (2010). El derecho y sus circunstancias: nuevos ensayos de filosofía jurídica. Bogotá: Universidad Externado de Colombia.

García Jaramillo, L. (2008). El "nuevo derecho" en Colombia: ¿entelequia innecesaria o novedad pertinente? Revista de Derecho Universidad del Norte, 289-330.

Kennedy, D. (2004). La educación legal como preparación para la jerarquía. Academia-Revista sobre enseñanza del derecho, 117-147.

Kennedy, D. (2006). La crítica de los derechos en los Critical Legal Studies. Revista Jurídica Universidad de Palermo, 47-90.

Kennedy, D. (2010). Izquierda y derecho. Ensayos de teoría jurídica crítica. Buenos Aires: Siglo XXI Editores.

Lascarro, C. (2012). De la hegemonía (neo) constitucional a la estrategia del nuevo constitucionalismo latinoamericano. Revista Jurídica Universidad de Caldas, 59-69. 
Montoya, J. (2008). Educación jurídica en América Latina: dificultades curriculares para promover los temas de interés público y justicia social. El otro derecho No.38, 29-42.

Morales de Setién, C. (2000). La racionalidad jurídica en crisis: Pierre Bourdieu y Gunther Teubner. En P. Bourdieu, \& G. Teubner, La fuerza del derecho (págs. 13-80). Bogotá: Siglo del Hombre Editores.

Mouffe, C. (1999). El retorno de lo político. Barcelona: Paidós.

Pérez, R. (2004). Los abogados de América Latina. Bogotá: Universidad Externado de Colombia.

Pozzolo, S. (1998). Neoconstitucionalismo y especificidad de la interpretación constitucional. DOXA-21-II, 339-353.

Quijano, A. (1992). Colonialidad y modernidad/racionalidad. Perú Indígena, 11-20.

Rodríguez Garavito, C. (1997). La decisión judicial: El debate Hart-Dworkin. Bogotá: Siglo del Hombre Editores.

Salazar Bondy, A. (1968). ¿Existe una filosofía de nuestra América? México: Siglo XXI Editores.

Sanín Restrepo, R. (2009). Teoría Crítica Constitucional. Bogotá: Pontificia Universidad Javeriana, Facultad de Ciencias Jurídicas: Grupo Editorial Ibañez.

Santos, B. (2010). Refundación del Estado en América Latina. Perspectivas desde una epistemología del Sur. Bogotá: Siglo del Hombre Editores; Universidad de los Andes; Siglo XXI Editores.

Saucier, J.-P. (2015). De Profesores, Chamanes y Curanderos: Hacia una ética de la violencia en la educación legal. Derecho y sociedad \#45, 403-414. 
Schaff,A. (1967) Lenguaje y conocimiento. México: Editorial Grijalbo

Tuori, K. (1998). Positivismo crítico y derecho moderno. México: Fontamara.

Veronelli, G. (2016). Sobre la colonialidad del lenguaje. Universitas Humanística, 33-58.

Villavicencio, S. (2007). Ciudadanía y civilidad: acerca del derecho a tener derechos. Colombia Internacional, 36-51.

Waldron, J (2012). Constitucionalism: a skeptical view. NYU School of Law, Public Law Research Paper No. 10-87

Wittgenstein, L. (1989). Conferencia sobre ética. Barcelona: Editorial Paidós.

Zagrebelsky, G. (2003). El derecho dúctil. Madrid: Trotta. 